\title{
Surveying the Role of Family Function and Curricular Self-Regulation in Curricular Burning out among Bushehr high School Students, Iran's Aspect
}

\section{Behroozi M*}

Department of Management, Bushehr Branch, Islamic Azad University, Bushehr, Iran

\begin{abstract}
The main purpose of this paper is to Survey the role of family function (FF) and curricular self-regulation (CS) in curricular burning out (CB) among Bushehr students. This is a descriptive-surveying research whose study population was 1958 students among which 362 persons were randomly selected as the sample based on multiclustering sampling method. Data were gathered via two standard questionnaires including Berso' curricular burning out, Kanel's self-regulation, and Opstien's family function). Some descriptive and inferential indices were applied to analyse the collected data using Amos-21. Findings, according to SEM, showed that the acquired model had an acceptable goodness fitness representing $72 \%$ of the curricular burning out variance by family function and curricular self-regulation while $18 \%$ of curricular self-regulation could be predicted by family function.
\end{abstract}

Keywords: Institutionalization; Ultimatum game; Social decisionmaking; Adolescence; EEG correlation; Early deprivation

\section{Introduction}

Today, the decrease of individuals' interest towards studies, specifically boys, refers to the lack of appropriate and merit job market for graduates and therefore, it is one of the most serious factors in decreasing interest about studies. It seems that students' interest about studies is getting low since there are no appropriate conditions for the graduates. Damages done by curricular burning out has brought up too much cost for government including waste of current expenditures of educational institutes, waste of constant investment, and also adequate harms for students including the expenditure of lost opportunity, being oppressed, feeling of being scorned, inadequacy, negative paradigm, and finally depression. There are some ways to face with burning out syndrome including decrease and removing of existing stresses in workplace, spiritual and emotional support by family, friends, and colleagues, getting consulting services for making negative attitudes and getting newly self-esteem aspiration, self-evaluation, changing bad and unacceptable working status to good and acceptable one. Recognition the effective variables on curricular burning out is one of the most essential matters and therefore, this paper is to survey the role of family function and curricular self-regulation on Bushehr students' curricular burning out using SEM approach.

\section{Review of Literature}

Newman [1] believes that the matter of curricular burning out is one of the most significant discussions raised in most of educational centres. He states that there would be various reasons for curricular burning out among which the most ones could be curricular burning out which makes curricular burning out among which the most ones could be curricular burning out which makes students' connections with university and faculties low; curricular burning out could affect the level of students' interest about studies continuity; curricular burning out could be used an important tool for identifying students' actions such as curricular performance during his/her studies. Those learners who would not like educational opportunities, they might possibly experience internal and external behaviour problems, psycho-physical issues, and lower life quality. Those who suffered from curriculum burning out, usually have some symptoms like unwillingness about studies, inability to be present continuously in classes, not taking part into classes actively, having no feeling and significance about lesson activities, inability about thinking and learning matters, and ultimately, they experience curricular drop. Family institute is one of the most effective factors affecting on burning out. Family as a system is an institute whose parts are being changed coincidently. Behaviour of members is a function of the others' behaviour and the family is also willing to make a balance as any other system; therefore, members' behaviour is to keep the balance totally. Ports believes that family ability to make coordination with created change, solving any conflicts and differences, coordination among whole members and achievement in disciplinary patterns, keeping limitation between individuals and ability to perform ruling laws and regulations are totally done to keep and protect family system and it is known as family function. Family is as a social institute being founded in society and regarding sociologists, family has a vital role to train any society active force, develop abilities and psychological health of individuals. The foundation of any early disagreement is based in family. In fact, any shortage in family function will bring up unacceptable impacts on individual's behaviour. Saperstein et al. studies showed that increasing curricular pressure and weak protection done by family has a relationship with psychological pressure and weak curricular paradigm. Students stress might have a positive relationship with socio-economic conditions, family status, teachers' teaching methods, school or faculty atmosphere, involvement and participation of parents, and personal traits. Curricular selfregulation is another main factor affecting curricular burning out. Researches and theories show that self-regulatory learning is a dominant strategy in training psychology. Accordingly, some theories

*Corresponding author: Behroozi M, Department of Management Bushehr Branch, Islamic Azad University, Bushehr, Iran, Tel: +987733534463; E-mail: dr_m_behroozi@yahoo.com

Received June 22, 2017; Accepted April 25, 2017; Published April 29, 2017

Citation: Behroozi M (2017) Surveying the Role of Family Function and Curricular Self-Regulation in Curricular Burning out among Bushehr high School Students, Iran's Aspect. Abnorm Behav Psychol 3: 132. doi: 10.4172/2472-0496.1000132

Copyright: (C) 2017 Behroozi M. This is an open-access article distributed under the terms of the Creative Commons Attribution License, which permits unrestricted use, distribution, and reproduction in any medium, provided the original author and source are credited. 
claim that contexts, relations and social conditions have important role in making or empowering self-ruling or self-regulation. Ruling conditions and ties over some social contexts causes to create some internal control feeling, choice perception, and willingness. In such a time, choosing the aim, planning, supervision, self-evaluation, and resource management are emerged or they are possibly likely to be emerged. Ways of self-regulation improves students' ability significantly and it causes the increase of achievement and self-control thus, organizing and regulating the main processes of learning and related activities are performed through curricular self-regulation. Strong indices of curricular self-regulation learning consist of self-evaluation, organizing, aim orientation; help research, contextual structures, and memory strategies which have positive relationship with curricular achievement. According to Smilley and Yavul self-regulation is not increased unless social context is concerned. Also Hoy's study shows that there is a relationship between self-regulated learning process and motivational beliefs with students' curricular performance. Kristanto et al. [2] showed that analysis of Variance (ANOVA), Kruskal-Wallis and Bonferroni pairwise comparison tests were performed using Stata version 13. The prevalence of academic burnout after 6-8 weeks was revealed to be $17.4 \%$ and $73.5 \%$, respectively for moderate and high level of academic burnout respectively. Emotional eating (Eat) scores were significantly different over levels of academic burnout after 6-8 weeks ( $\mathrm{p}=0.0103$ ) while no significant differences was observed in other subscales such as cognitive restraint (CR) and uncontrolled eating (UE). These findings evidenced partial associations between academic burnout and eating disorder. Inbar [3] addresses the purpose of the paper is to examine all six school-work-family inter role conflicts and their effects on subjective stress and burnout. It was hypothesized that the greater the conflict between families, work, and school roles, the greater the subjective stress and burnout and that women experience more work-family-school conflicts than do men. Wulburg [4] the aim of the study was to explore current research concerning school-related burnout among high school students. Sixteen studies concerning school-related burnout and academic stress among high school students were reviewed. The review of these publications has highlighted a number of risk factors and mental health consequences concerning burnout in an adolescent population. Gaps regarding research in this field have also emerged, in particular the need for screening scales and repercussions on mental health.

\begin{tabular}{|c|c|c|}
\hline Fitness indices & Range & P-Value \\
\hline$\left(\mathrm{X}^{2} / \mathrm{df}\right)$ & $\geq 3$ & 3.78 \\
\hline $\mathrm{CFI}$ & $\leq 0.9$ & 0.93 \\
\hline RMSEA & $\geq 0.9$ & 0.087 \\
\hline
\end{tabular}

Table 1: Fitness indices of causative model of FF and SR on CB.

\section{Methodology}

This is a descriptive-surveying research in which an SEM was applied to test the model. Study population was 1958 students among which 362 persons were randomly selected as the sample based on multi-clustering sampling method using Cochran's formula. Data were gathered via three standard questionnaires including Berso' curricular burning out consisting of 15 items asking about curricular tiresome, curricular unwillingness, and curricular inefficacy, Kanel's selfregulation consisting of 32 items asking about internal self-regulation, external self-regulation, cognitive self-regulation, and internal motivation, and opstien's family function consisting of 60 items asking about problem solving, relations, roles, effective accountability, effective involvement, behaviour control, general function.

\section{Findings and Discussion}

Based on the model of research concept, the model of the impact of family function and curricular self-regulation on curricular burning out was analysed through using Amos-21. This model has one latent external variable and two latent internal variables which were family function and curricular self-regulation and curricular burning out.

Findings showed that the model had acceptable goodness fitness though Chi Square index did not support the given model; however, the two other indices meaning CFI and RMSEA supported the model (Table 1). The path of family function towards curricular burning out, towards curricular self-regulation, and the path of curricular self-regulation towards curricular burning out were significant $(\mathrm{P}>0.001)$ (Table 2). SEM has been shown to explain the curricular burning out along with path constant and factor loads for any variable (Figure 1). To explain this finding it must be said that although the modernization of life has affected family and it has brought up changes and transformations, family should not be seen as an inactive or passive unit accepting any changes merely rather than family can interchange actively. Healthy function of family and protection of this significant social institute about children in studies can make students get needed motivation for studies and leave any tiresome feeling or pessimistic view about schooling or learning. Warm relations and emotions and good emotional joint and commitment of any family can bring up kids, children, and offspring good feelings to believe that they are accepted by their parents and their parents, in turn, are responsible and sensible towards their willing and requests. This acceptance makes a calmness, comfortable conditions for children; consequently, these children are to try to get good traits such as agreeable and compatible behaviours, curricular efficacy, effective communications based on society norms, self-esteem increasing, stress decreasing, and having hopeful status.

\begin{tabular}{|c|c|c|c|c|c|}
\hline \multicolumn{3}{|c|}{ Structural Paths } & $\beta$ & C.R. & P-Value \\
\hline $\mathrm{FF}$ & & CB & -0.71 & -5.72 & 0.001 \\
\hline $\mathrm{FF}$ & $\longrightarrow$ & $\mathrm{CR}$ & 0.42 & 6.17 & 0.001 \\
\hline CR & $\longrightarrow$ & CB & -.25 & 3.93 & 0.001 \\
\hline
\end{tabular}

Table 2: Constants of causative structural model of $\mathrm{CB}$.

\begin{tabular}{|c|c|c|c|c|c|}
\hline \multirow{2}{*}{} & \multicolumn{3}{|c|}{ CB } & \multicolumn{2}{c|}{ CSR } \\
\cline { 2 - 5 } & Direct & Indirect & Total & Direct & Indirect \\
\hline FF & -0.71 & -0.11 & -0.82 & - & 0.42 \\
\hline CSR & -0.25 & - & -0.25 & - & - \\
\hline Explained Variance & & 0.72 & & - \\
\hline
\end{tabular}

Table 3: Calculations of direct and indirect impacts of model on each other. 


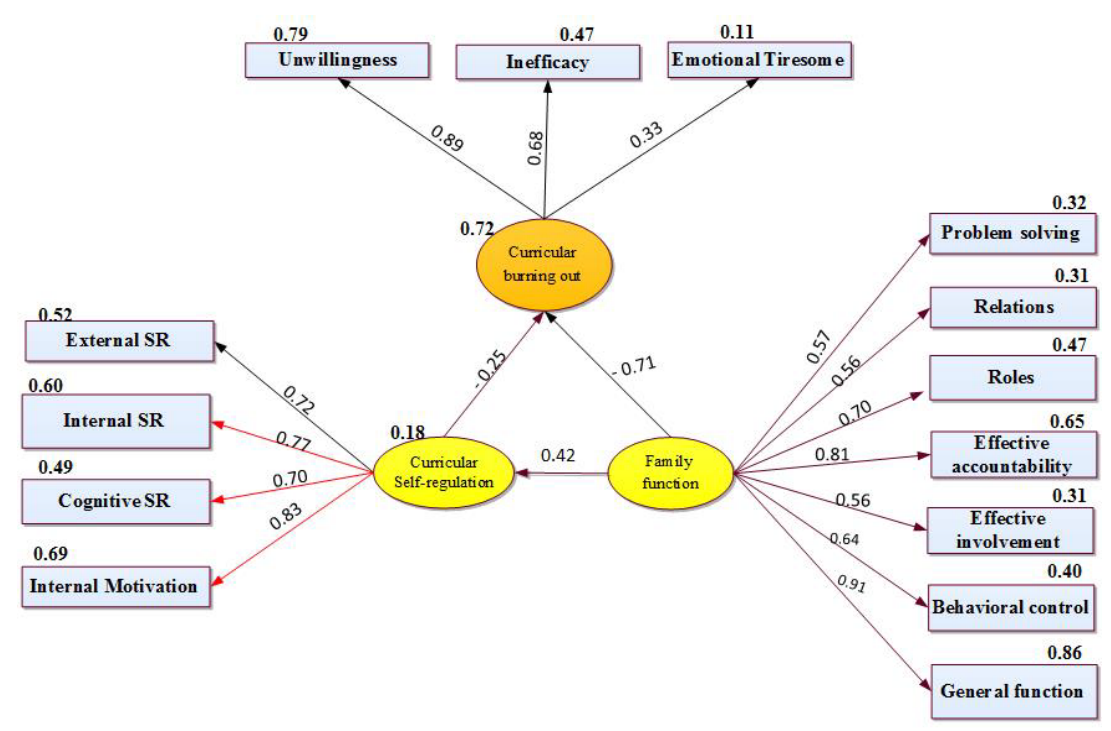

Figure 1: SEM for explanation of $\mathrm{CB}$.

On the other hand, those families having negative relations among themselves and continual conflicts and differences, automatically get tendency towards conflict about anything and anybody even children and their behaviours and surely it makes children aggressive ones who make problems for themselves and their contexts. So many of behavioural disorders are seen in families which are ruled by aggressive manners and communications become threaten for children. Some theorists believe that emerging or continuity of aggressive signs are based on using repeated useless solutions while facing various issues; therefore, increasing the skill of problem solving and family decisionmaking will lessen the emerge of behavioural problems among family members and thus, children feel safe (Table 3). Accordingly, weak communicative skill of family can affect or create children behavioural problems, so the more stronger skill; the less conflict will be created. The healthy function of family can make students' curricular burning out completely.

\section{Suggestions}

Concerning the family function can make happiness and enjoyment for children, so the role of family for making any decision should be concluded and the workshops for promotion of family's view about life and behaviours must be included continually.

\section{Acknowledgements}

The authors would like to thank those teachers and trainers who have tried hard to make family's attitude promote.

\section{References}

1. NeumanY (1990) Quality of learning experience and students college outcomes. International Journal of Educational Management 7: 1-16.

2. Kristanto T, Sun CW, Thoo YY (2016) Academic burnout and eating disorder among students in Monash University Malaysia, Eating Behaviors 22: 96-100.

3. Inbar K (2016) the relationship between school-work-family-conflict, subjective stress, and burnout. Journal of Managerial Psychology 31: 805-819.

4. Walburg V (2014) Burnout among high school students 42: 28-33. 